\title{
Using Surface Response Models to Evaluate the Effects of Kinetin on Dioscorea alata Propagated in Vitro
}

\author{
Charles Nelimor ${ }^{1,2}$, Henry Yabbey Sintim ${ }^{1,3}$, Alexander Wireko Kena ${ }^{1,4}$ and Richard Akromah ${ }^{1}$ \\ 1. Department of Crop and Soil Sciences, Kwame Nkrumah University of Science and Technology, PMB, Kumasi, Ghana \\ 2. Department of Biosciences, Université Félix Houphouët-Boigny, BP 22, Abidjan, Cote D'lvoire \\ 3. Department of Crop and Soil Sciences, Washington State University, 2606 West Pioneer, Puyallup, WA 98371, USA \\ 4. Department of Agronomy, Horticulture \& Plant Science, South Dakota State University, Brookings, SD 57007, USA
}

\begin{abstract}
Kinetin is an important growth hormone used for in vitro propagation, but its dynamic and temporal effects on Dioscorea alata have not been thoroughly evaluated. In this study, surface response models were developed to better elucidate the effects of kinetin on D. alata propagated in vitro. Nodal segments were obtained from Akaaba, an important D. alata cultivar in Ghana, and propagated in vitro under five kinetin rates $(0,2.5,5,7.5$ and $10 \mu \mathrm{M})$. The models were developed using segmented multiple regression with time and kinetin as the predictors. The effects on plant height, the number of leaves, shoots and roots were assessed with three-dimensional figures for better observation of temporal trends. The model fit was very good with normalized root mean squared error $($ NRMSE) $=0.1, R$-squared $=0.83$ and adjusted $R$-squared $=0.82$, averaged across the different growth parameters . Different kinetin levels elicited the maximum shoot, leaf and root formation, as well as the growth rates over time. Moderate kinetin levels $(2-4 \mu \mathrm{M})$ provided better growth at early culturing period. Higher kinetin levels $(5-10 \mu \mathrm{M})$ suppressed the growth of the plantlets at early stages, but the plantlets recovered from the stress and resumed normal growth thereafter. After 4-5 weeks, the growth rates of the moderate kinetin levels $(2-4 \mu \mathrm{M})$ declined much faster and were lower compared to the higher kinetin levels, except plant height and the number of roots which were still higher at the moderate kinetin level even after eight weeks of culturing. Thus, kinetin requirements vary depending on the growth parameters of interest.
\end{abstract}

Key words: Water yam, tissue culture, nodal explant, kinetin, surface response model.

\section{Introduction}

Yam, a tuber crop belonging to the family Dioscoreaceae, is a security food crop serving as important staple to millions of people worldwide [1, 2]. Yam is also a major source of income and forms part of the socioeconomic life of many people, especially in West Africa [1, 3]. The world production of yam in 2014 was 68.1 million tons, with West Africa producing more than 91\% [4]. According to Aighewi et al. [5], Dioscorea alata is the second most important edible species of the genus Dioscorea, which has over 600 species. Most $D$. alata cultivars are late-maturing with long shelf-life, thus $D$. alata helps to fill the demand for yam food when all other

Corresponding author: Richard Akromah, professor, research fields: plant breeding and genetics. yams are out of season [6, 7].

The lack of quality planting materials for D. alata in West Africa has been a major production constraint, which is also true for all other edible yam species [8-10]. Traditionally, small whole tubers or minisetts cut from large tubers are the main sources of planting materials. In West Africa, most farmers use tubers saved from previous season for propagation. These are often prone to pests and diseases, leading to poor yield and quality [5, 11]. Moreover, yam propagation by this method is slow and inefficient for rapid multiplication.

The application of plant tissue culture in circumventing the limitations of traditional field propagation methods has been well elucidated in many economically important crop species [12-14]. The practice is done in an automated laboratory 
environment which is free from fluctuating weather conditions. Production cycles can therefore be well planned, as well as clean, high quality and uniform plants can be produced [15]. Tissue culture provides a rapid method of multiplying disease-free and improved cultivars for production, breeding programs and research work [5]. Additionally, tissue culture is very essential for germplasm conservation of vegetative propagated crops, alleviating losses from pests and diseases, drought stress, wild fires and thefts associated with field conservation, especially in developing countries $[14,16]$.

A number of methods are available for in vitro propagation of $D$. alata, such as the formation of callus from stems, leaves or petiole explants, and then subsequent regeneration of the callus using multiple growth hormones [3, 17]. This method is quite cumbersome, time consuming and it requires high level of expertise. Also, callus formation can sometimes cause somaclonal variation, a condition that is often undesirable for conservation and propagation purposes, because it can alter the genetic fidelity of plantlets [16, 18]. Other in vitro propagation methods for $D$. alata involve the use of nodal segments, in combination with multiple growth regulators, to promote direct regeneration of the plantlets [19-22]. Overall, the direct regeneration methods are often desired, because in vitro plantlets can be obtained within a short period, plus it maintains the genetic fidelity of plantlets.

Kinetin is an important growth hormone used for in vitro propagation of $D$. alata [3, 23], but the reported effects of kinetin on in vitro yam plantlets differ, especially on shoot and root formation [3, 23-25]. Kinetin is often reported to have significant effects on shoot formation and very little effects on root formation; however, a number of studies have also observed significant effects of kinetin on root formation, as well as varying effects on the shoot formation of D. alata [3, 23-26]. Here, surface response models were developed to better evaluate the effects of kinetin on D. alata propagated in vitro.

\section{Materials and Methods}

\subsection{Experimental Materials and Disinfection of Explants}

D. alata cultivar Akaaba in Ghana, weighing approximately $500 \mathrm{~g}$, was cut into minisetts of about $25 \mathrm{~g}$ each. The freshly cut minisetts were treated in a suspension containing wood ash and allowed to dry by spreading in light shade for $2 \mathrm{~d}$. The sets were pre-sprouted in moist tissue paper. They were then transferred into plastic pots containing sterilized sandy loam soil one week after sprouting, and grown in a plant house at the Department of Crop and Soil Sciences, Kwame Nkrumah University of Science and Technology, Kumasi, Ghana. After four weeks, the leaves of the plants were trimmed and the shoots were cut into single node segments of 2-2.5 cm long. The nodal segments were washed in tap water for some time and then transported to the plant tissue culture laboratory for preparation and subsequent in vitro establishment. Under the laminar air flow cabinet, the node segments were disinfected by soaking in $70 \%$ ethanol for $2 \mathrm{~min}$, followed by rinsing with five changes of sterile distilled water. Disinfection was continued with $10 \%$ sodium hypochlorite (v/v) containing four drops of Tween-20 (polyoxyethylene (20) sorbitan monolaurate) for $15 \mathrm{~min}$. The disinfected explants were rinsed with several changes of sterile distilled water and allowed to air-dry under the laminar air flow cabinet before inoculation.

\subsection{Growth Medium and Inoculation}

The Murashiege and Skoog (MS) basal medium was prepared and then amended with $30 \mathrm{~g} / \mathrm{L}$ sucrose and $3.5 \mathrm{~g} / \mathrm{L}$ phytagel (Sigma-Aldrich Co., LLC, Saint Louis, MO, USA). The medium was placed on a hot magnetic stirrer, which provided heat to dissolve the phytagel. Five lots were prepared and kinetin concentrations of $0,2.5,5,7.5$ and $10 \mu \mathrm{M}$ were added to each medium. The media were adjusted to $\mathrm{pH} 5.8$ 
and dispensed into test tubes in aliquots of $10 \mathrm{~mL}$ each while they were hot. The test tubes were capped and autoclaved at a temperature of $121{ }^{\circ} \mathrm{C}$ and pressure of $103.4 \mathrm{kPa}$ for $20 \mathrm{~min}$. The media were allowed to cool after autoclaving, and then stored in a refrigerator at $4{ }^{\circ} \mathrm{C}$ until they were required for inoculation.

The sterilized explants were held with sterilized pairs of forceps, while a surgical blade was used to trim the explants to about $3 \mathrm{~mm}$ below the node and 5 $\mathrm{mm}$ above the node. The explants were immediately removed and inoculated, using one explant per test tube. The entire process was performed under the laminar flow hood to minimize contamination. Also, the surgical blade and the pair of forceps were sterilized, after each explant was inoculated to avoid cross contamination. The inoculated cultures were incubated in a growth room programmed to provide 8 $\mathrm{h}$ of darkness and $16 \mathrm{~h}$ of light $\left(47.3 \mu \mathrm{mol} / \mathrm{m}^{2} \cdot \mathrm{s}\right.$ light intensity) every day. The temperature and relative humidity were set to $24 \pm 2{ }^{\circ} \mathrm{C}$ and $70 \%$, respectively.

\subsection{Statistical Analyses and Model}

The experiment was laid out in a completely randomized design with six replications, where the five kinetin levels served as the treatments. Data on plant height and the number of roots, shoots and leaves were collected for four consecutive 2-week periods. The $R$ statistical package (version 3.3.2) [27] was used for all statistical analysis, model development and figures. First, repeated measure analyses were performed on all measured growth parameters. The results showed significant interactions of kinetin level $\times$ time on the measured growth parameters $(p<0.001)$; thus, surface responses models using segmented multiple regression were developed and used to predict the effects of kinetin over time on in vitro D. alata plantlets. Conditions set for the segments of plant height, number of leaves and number of shoots were in Eq. (1), and conditions for the number of roots in Eq. (2):

$$
\begin{aligned}
& \text { TY }(k, t)=\left\{\begin{array}{c}
0(t<0.43 ; m r q \leq 0) \\
m r q(0.43 \leq t \leq 8)
\end{array}\right. \\
& T Y(k, t)=\left\{\begin{array}{c}
0(t<2 ; m r q \leq 0) \\
m r q(2 \leq t \leq 8)
\end{array}\right.
\end{aligned}
$$

where, $T Y(k, t)$ is the predicted transformed growth parameter as function of time and kinetin; $\mathrm{mrq}$ is the solution of the multiple regression function (Table 1); the constants 0.43 and 2 are the time threshold (measured in week) at which growth begins, and the constant 8 is the maximum observation period of the study. The predicted transformed growth can be back transformed to original measured scale using Eq. (3).

$$
Y(k t)=\left\{\begin{array}{c}
0(T Y=0) \\
\exp (m r q)+c(T Y>0)
\end{array}\right.
$$

where, $Y(k t)$ is the back transformed predicted growth parameter, and $c$ is a constant, which represent the range of observed growth parameter divided by two.

\begin{tabular}{|c|c|c|c|c|}
\hline $\begin{array}{l}\text { Growth } \\
\text { parameters }\end{array}$ & Model parameters ${ }^{*}$ & $R$-squared & $\begin{array}{l}\text { Adjusted } \\
R \text {-squared }\end{array}$ & NRMSE \\
\hline Plant height & $I=0.76 ; S_{t 2}=0.01, S_{t 3}=0.001 ; S_{k 1}=0.55, S_{k 2}=-0.11, S_{k 3}=0.01$ & 0.91 & 0.90 & 0.08 \\
\hline Number of shoots & $\begin{array}{l}I=0.68 ; S_{t 1}=0.01, S_{t 2}=-0.01 ; S_{k 1}=0.340, S_{k 2}=-0.08, S_{k 3}=0.004 \\
S_{t k}=0.004\end{array}$ & 0.77 & 0.75 & 0.13 \\
\hline Number of leaves & $I=1.04 ; S_{t 1}=0.07 ; S_{k 1}=0.48, S_{k 2}=-0.1, S_{k 3}=0.01$ & 0.80 & 0.79 & 0.10 \\
\hline Number of roots & $I=1.88 ; S_{t 2}=0.01 ; S_{k 1}=0.49, S_{k 2}=-0.12 ; S_{k 3}=0.01$ & 0.85 & 0.83 & 0.08 \\
\hline
\end{tabular}

Table 1 Model parameters, normalized root mean square (NRMSE), $R$-squared and adjusted $R$-squared of models that described the effects of kinetin on plant height, number of leaves, shoots and roots of $D$. alata plantlets propagated in vitro.

I: intercept; $S_{t 1}, S_{t 2}, S_{t 3}$ : the coefficients of the slope with respect to time and number subscript indicating power functions; $S_{k 1}, S_{k 2}, S_{k 3}$ : the coefficients of the slope with respect to kinetin and number subscript indicating the power function; $S_{t k}$ is the coefficient of time and kinetin interaction.

${ }^{*}$ These parameters represent coefficients to obtain transformed values of the predicted growth parameters. 
The constants were 2.55 for plant height, 2.5 for the number of shoots, 4 for the number of leaves, and 7.5 for the number of plant root.

The model selection process was guided by assessing the Akaike information criterion (AIC), normalized root mean square error (NRMSE; normalized to the range of observed data) and adjusted $R$-squared. Also, model assumptions were assessed and that necessitated transformation of the observed growth parameters.

\section{Results}

\subsection{Observed Growth of Cultures}

Regeneration of cultures was observed within 5-8 d after inoculation, except the control $(0 \mu \mathrm{M}$ kinetin) where signs of growth occurred after five weeks. In general, the kinetin treatments enhanced the growth of plantlets compared to the control. Actually, the number of roots was the only parameter in which the control treatment showed signs of growth (Fig. 1). There was no callus formation in all the cultures, but the explants underwent direct regeneration. Oxidative browning was also observed in the cultures (Fig. 1), but it had a minimal effect on the general growth of the plantlets.

\subsection{Model Fit}

Overall, the model fit was very good, having low NRMSE and high $R$-squared and adjusted $R$-squared (Table 1). The three criteria were also consistent in terms of their interpretation; where $R$-squared and adjusted $R$-squared were the greatest, the NRMSE was the least. The fit for plant height was the best, followed by the number of roots and the number of leaves, and the least was the number of shoots.

\subsection{Effects of Kinetin on Plant Height}

The results showed complex surface curvatures (Fig. 2) in plant height, indicating varying physiological responses of the in vitro plantlets to different kinetin levels. There was a cubic response in plant height with increasing kinetin levels and also over time (Table 1). Growth was low below $2 \mu \mathrm{M}$ kinetin, but moderate kinetin levels $(2.2-5.6 \mu \mathrm{M})$ were ideal for providing early growth advantage. As the kinetin concentration increased beyond those levels, the plant height decreased substantially again. There was a concave curvature at 5.8-10 $\mu \mathrm{M}$ kinetin with respect to time that tapered at week 5 (Fig. 2b). This may suggest that the kinetin level was too high for the



Fig. 1 Cultures showing in vitro plantlets of $D$. alata in growth medium of different kinetin levels after eight weeks of inoculation. 
young plantlets, thus suppressing their growth. The plantlets, however, recovered from the stress and resumed normal growth thereafter. Thus, the tolerable range for kinetin concentration became wider over time. The growth rate of plant, including plant height, numbers of leaf, root and shoot, is shown in Fig. 3. For plant height, the growth rate increased with time until week 5, and afterwards it declined (Fig. 3a). At week 5, $3.54 \mu \mathrm{M}$ kinetin level elicited the maximum growth rate, which was $0.32 \mathrm{~cm} /$ week. Also, at week 8 , $3.52 \mu \mathrm{M}$ kinetin level elicited the maximum growth rate $(0.17 \mathrm{~cm} /$ week $)$. The maximum plant height estimated at week 8 was $4.17 \mathrm{~cm}$.

\subsection{Effects of Kinetin on Number of Shoots}

The effects of kinetin on the number of shoot formed were to a lesser extent, with the estimated maximum of only 3.08 shoots per plantlet at week 8 (Fig. 4). This occurred at $3.55 \mu \mathrm{M}$ kinetin level. The number of shoots formed per week peaked at 0.41 , and it was observed after week 4 at $10 \mu \mathrm{M}$ kinetin level (Fig. 3b). Also, at week 8, the $10 \mu \mathrm{M}$ kinetin level elicited the greatest number of shoots formed per week (0.31). Noticeable physiological response from the 3-dimensional figure of the surface response model (Fig. 4b) was an intrinsic delay of shoot formation. The $3 \mu \mathrm{M}$ kinetin level induced shoot formation the earliest, whereas the higher kinetin levels $(5-10 \mu \mathrm{M})$, generally, prolonged the onset of shoot formation.

\subsection{Effects of Kinetin on Number of Leaves}

The effects of kinetin on leaf formation were very similar to that of the effects on shoot formation, but more leaves were formed. Leaf formation was very low at 0-2 $\mu \mathrm{M}$ kinetin levels and 5-9 $\mu \mathrm{M}$ kinetin levels (Fig. 5). However, 2-5 $\mu \mathrm{M}$ kinetin level and $>9$ $\mu \mathrm{M}$ kinetin level elicited faster and greater leaf formation. The maximum number of leaves formed within the predicted range was 6.48 roots per plantlet, and it was induced by $10 \mu \mathrm{M}$ kinetin level. Also, the leaf growth rate (number of leaves formed per week) within the predicted range was at the maximum (0.708) at week 8 (Fig. 3c). This was induced by $10 \mu \mathrm{M}$ kinetin level. At 2-4 $\mu \mathrm{M}$ kinetin levels, there was a convex curvature with respect to time, but at 5-10 $\mu \mathrm{M}$

a

Plant height $(\mathrm{cm})$

b

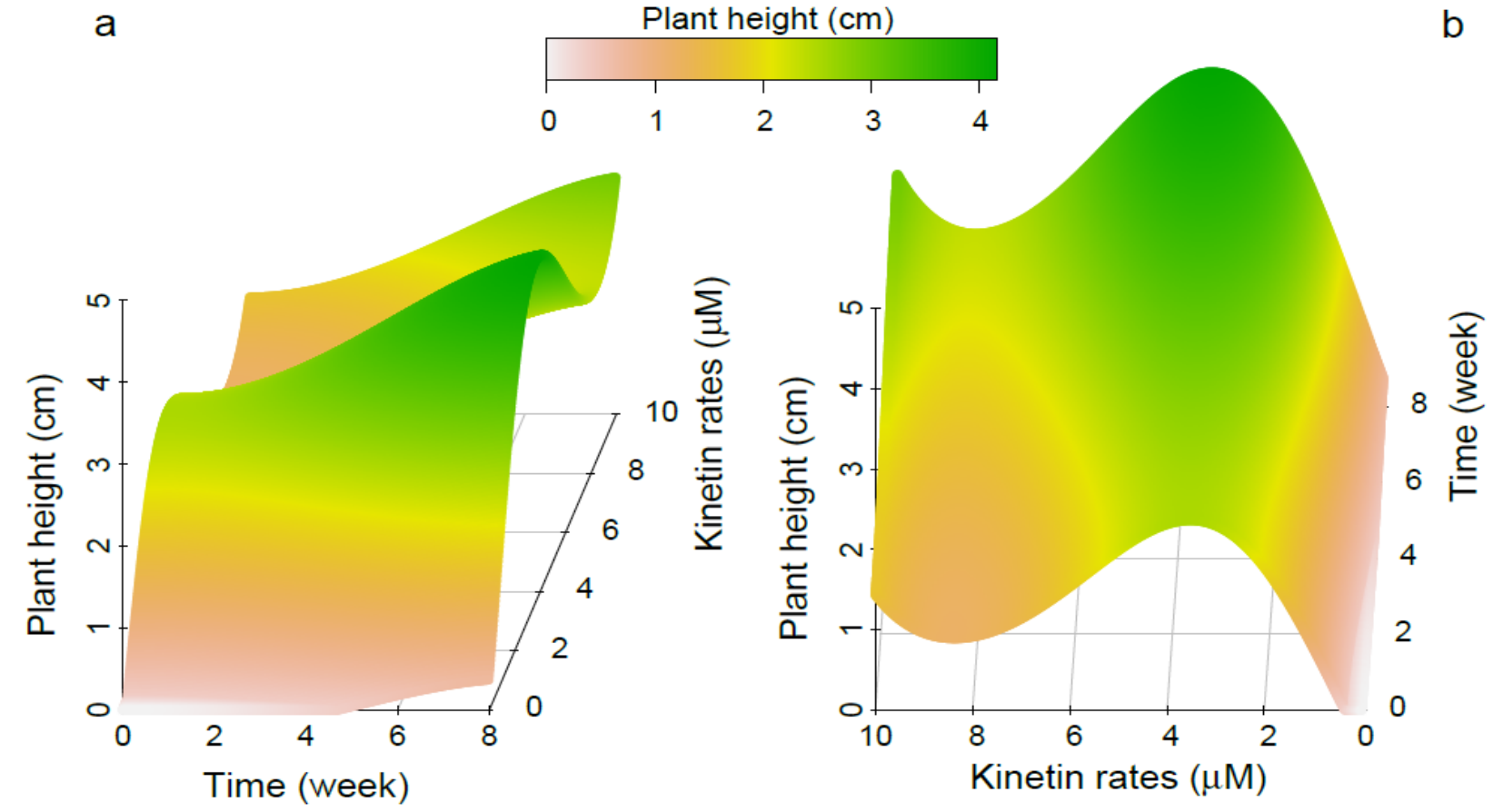

Fig. 2 Time and kinetin effects on plant height of $D$. alata plantlets propagated in vitro.

Figs. 1a and $1 \mathrm{~b}$ are the same, but rotated in time and kinetin dimensions, respectively. 

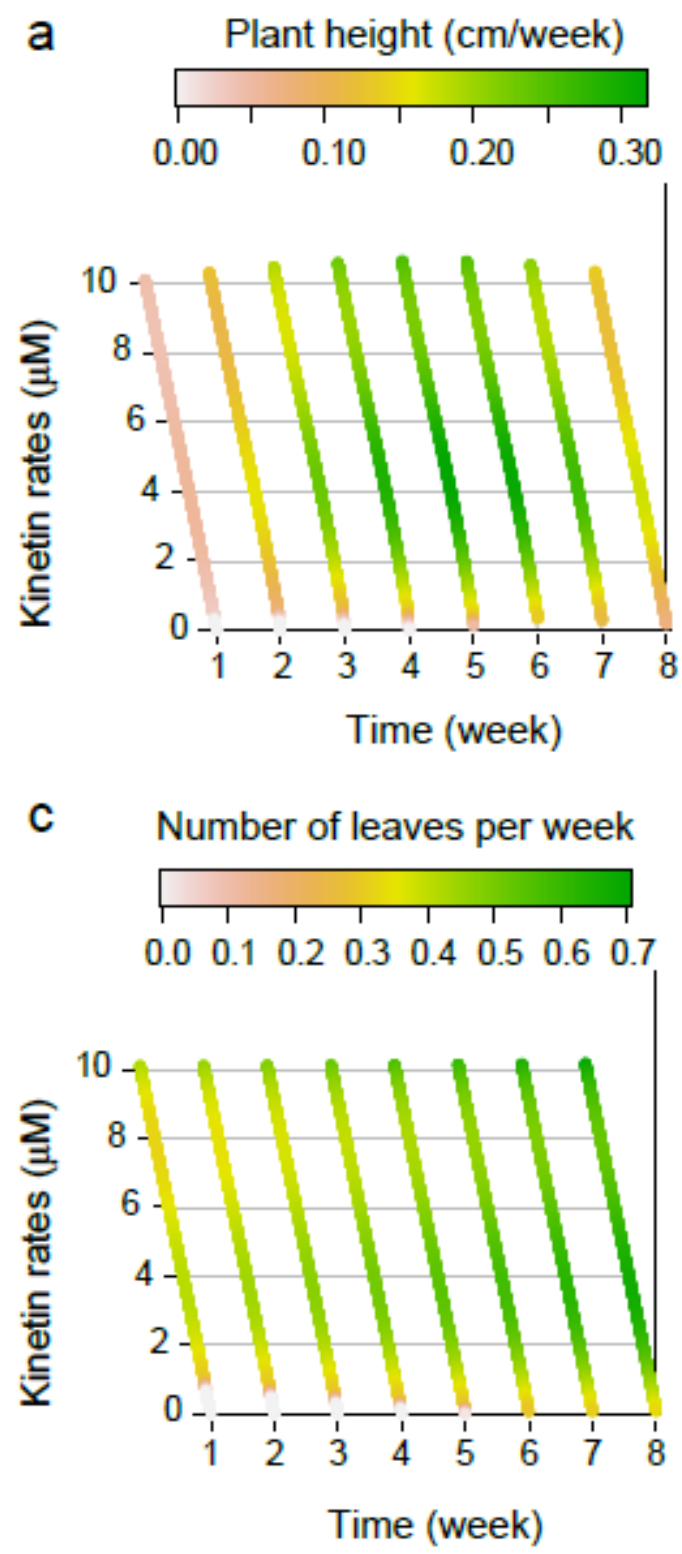

Fig. 3 Growth rates of $D$. alata plantlets propagated in vitro.

kinetin levels, the curvature was concave (Fig. 5b). This could be an indication of the plantlets resuming growth from dormant stage in the former, and a growth suppression in the later.

\subsection{Effects of Kinetin on Number of Roots}

The results showed a very narrow range in which kinetin $(2-4 \mu \mathrm{M})$ had high effects on the number of roots formed (Fig. 6). Also, there was a very long delay of root formation, but the root growth increased at an exponential rate thereafter. The maximum b

Number of shoots per week
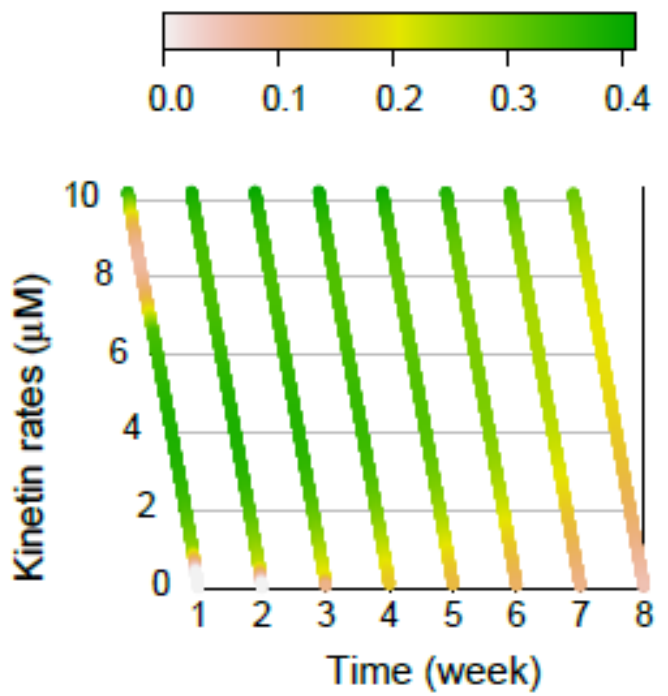

d

Number of roots per week
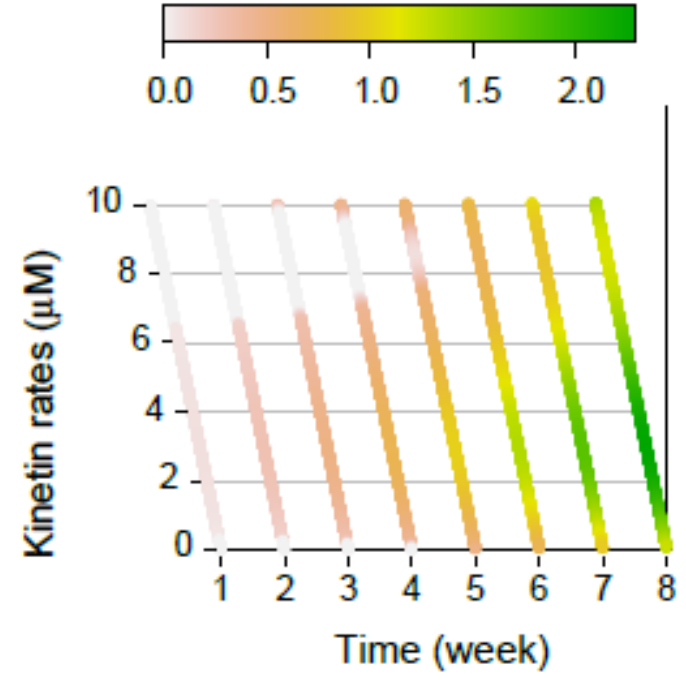

number of roots formed within the predicted range was 12.4 roots per plantlet, and it was induced by 2.75 $\mu \mathrm{M}$ kinetin level. Also, the root growth rate (number of roots formed per week) within the predicted range was at the maximum (2.29) at week 8 (Fig. 3d). This was also induced by $2.75 \mu \mathrm{M}$ kinetin level. At 2-4 $\mu \mathrm{M}$ kinetin levels, there was a convex curvature with respect to time (Fig. 6b), which indicated the resumption of growth by the plantlets. There was no concave curvature observed within the kinetin levels used for the model prediction. This was interesting 



Fig. 4 Time and kinetin effects on shoot formation of $D$. alata plantlets propagated in vitro.

Figs. $1 \mathrm{a}$ and $1 \mathrm{~b}$ are the same but rotated in time and kinetin dimensions, respectively.

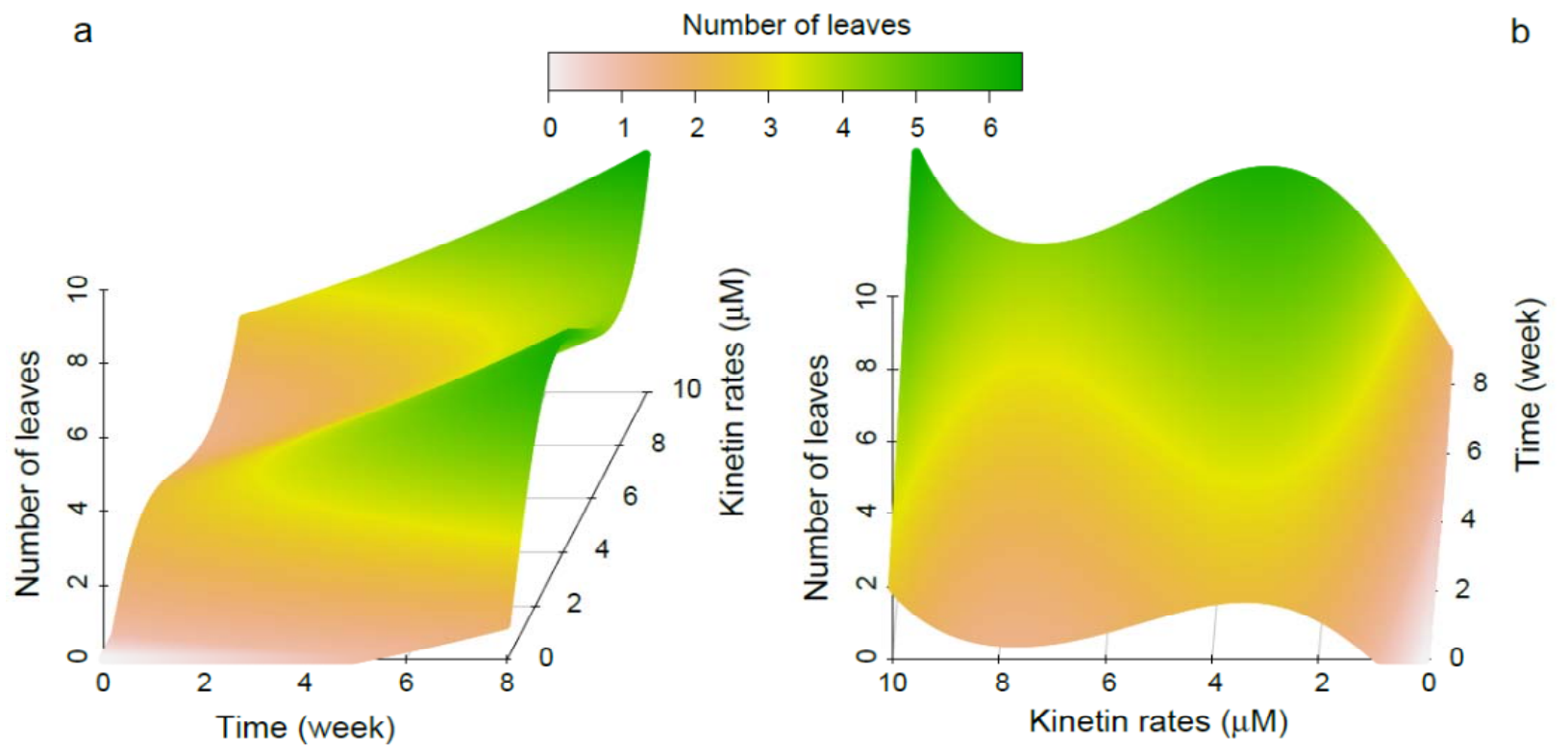

Fig. 5 Time and kinetin effects on leaf formation of $D$. alata plantlets propagated in vitro.

Figs. $1 \mathrm{a}$ and $1 \mathrm{~b}$ are the same but rotated in time and kinetin dimensions, respectively.

because concave curvatures were found in all the other growth parameters. Thus, the kinetin levels evaluated in this study did not suppress root formation of $D$. alata. Roots were formed even at the $0 \mu \mathrm{M}$ kinetin level (4.35 roots per plantlet), which suggest that other factors may have had more pronounced effects on root formation and their interaction with specific levels of kinetin induced synergistic effects.

\section{Discussion}

The lack of quality planting materials is a major drawback in yam production, thus tissue culture is often the method used for multiplying disease-free and improved cultivars. In this study, the use of node 


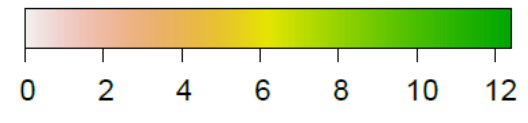

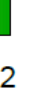
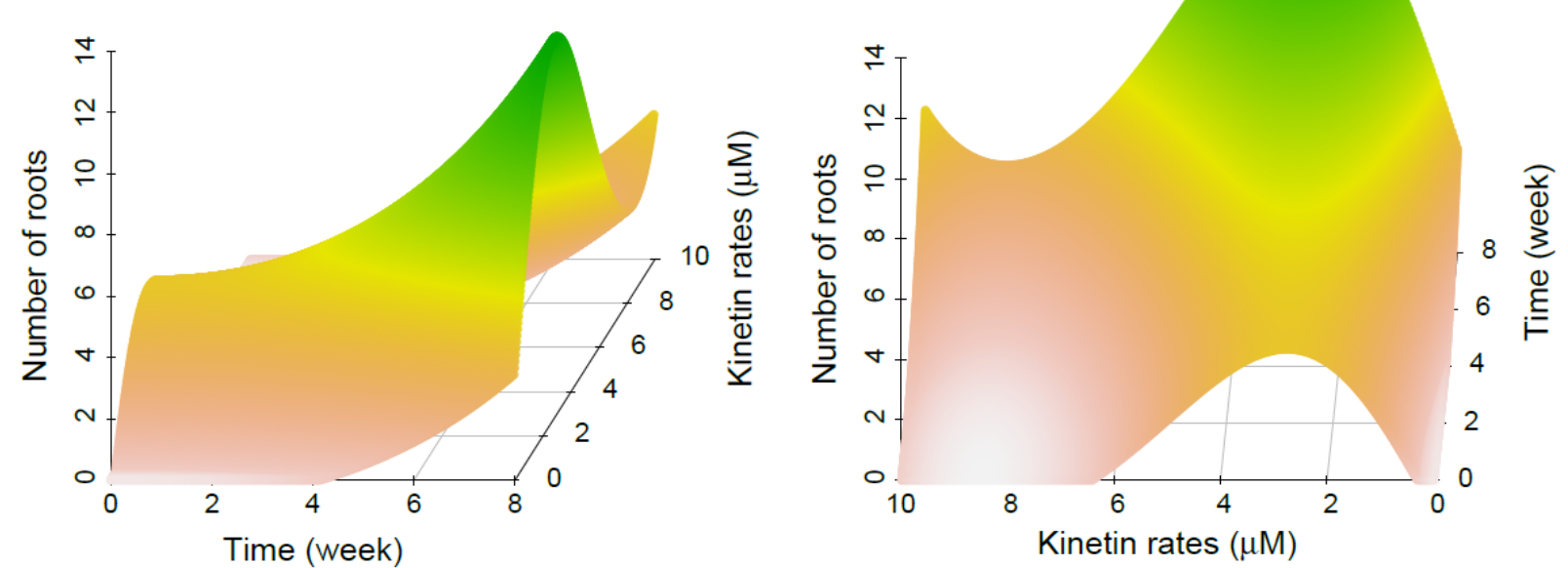

Fig. 6 Time and kinetin effects on the root formation of $D$. alata plantlets propagated in vitro.

Figs. $1 \mathrm{a}$ and $1 \mathrm{~b}$ are the same but rotated in time and kinetin dimensions, respectively.

segments and MS medium amended with kinetin as the only growth hormone promoted direct regeneration of Akaaba, a D. alata cultivar, without callus formation. In addition, the general growth performance of the plantlets was good. More importantly, different kinetin levels elicited the maximum shoot, leaf and root formation, as well as the growth rates over time.

Growth and morphogenetic response of in vitro cultures depend on the carbon source and the constituents and balances of growth regulators present in the growth medium [14, 28-30]. Production of plantlets with profuse rooting in vitro is important for successful establishment of regenerated plantlets in soil. The number of roots formed per plantlet after eight weeks (13 for observed and 12.4 for predicted) was very high, and even it was also fairly high (5 for observed and 4.35 for predicted) in the $0 \mu \mathrm{M}$ kinetin level. Fotso et al. [21] reported a range of 3.4-6.6 average numbers of roots per plantlet when they cultured D. alata with different combinations of kinetin, 6-benzylaminopurine (BAP) and 1-naphthaleneacetic acid (NAA). They were able to regenerate the plantlets in soil, even though some of the plantlets had lower number of roots compared to that of $0 \mu \mathrm{M}$ kinetin that was obtained in the current study. Previous studies have indicated that root formation is a high energy process that requires metabolic substrate, usually carbohydrate [14, 30]. Thus root formation in the hormone-free medium could be the result of sucrose that was added to the medium. However, specific levels of kinetin (2-4 $\mu \mathrm{M})$ induced synergistic effects resulting in the very high root formation.

In contrast to root formation, there was no response in plant height and the number of leaves and shoots to the hormone-free medium. Kinetin is a growth hormone known to promote cell division and is often used to regenerate shoot tissues from callus [26]. The number of shoots per plantlet after eight weeks of culture regeneration was at the maximum (3.08) at $3.55 \mu \mathrm{M}$ kinetin. However, the growth rate declined over time, and by week 8 , it was at the maximum (0.31 shoots formed per week) at $10 \mu \mathrm{M}$ kinetin. Poornima and Ravishankar [23] studied kinetin effects on two wild yams-D. oppostifolia and D. pentaphylla, and showed an average of 1.5 shoots per plantlet at 2.3 $\mu \mathrm{M}$ kinetin and 3.4 shoots per plantlet at $9.3 \mu \mathrm{M}$ kinetin for $D$. oppostifolia. However, the authors observed no effects of kinetin on $D$. pentaphylla, with an average of 1.4 shoots per plantlet. 
In micropropagation of $D$. oppostifolia, where Behera et al. [24] studied the effects of different rates of kinetin, but also amended the growth medium with $1.1 \mu \mathrm{M}$ BAP and $0.57 \mathrm{mM}$ of ascorbic acid, $9.3 \mu \mathrm{M}$ kinetin performed the best in terms of the number of shoots and height of plantlets. Also, Das et al. [25] evaluated the effects of different rates of kinetin, in combination with $11.4 \mu \mathrm{M}$ indole-3-acetic acid (IAA), on D. alata cultured in vitro with nodal segment, and observed that $7 \mu \mathrm{M}$ kinetin performed the best in terms of the number of shoots and height of plantlets. Mantell and Hugo [31] reported that $2.5 \mu \mathrm{M}$ kinetin level was adequate for microtuberization in $D$. alata shoot cultures. The results of these studies, somewhat, corroborates those of the current study.

Moderate kinetin level (2-4 $\mu \mathrm{M})$ was required to provide better growth at early culturing period. The higher kinetin levels (5-10 $\mu \mathrm{M})$ suppressed the growth of the plantlets at early stages. However, the plantlets recovered from the stress and resumed normal growth thereafter. Actually, the highest kinetin level used in this study $(10 \mu \mathrm{M})$ elicited the greatest shoot and leaf growth rates after eight weeks of culturing. Thus different kinetin levels would be optimal for $D$. alata depending on the age of the plantlets being tested. The growth parameter being used for evaluation is also very critical. This is because after 4-5 weeks, the growth rates (number of shoots and leaves) of the moderate kinetin levels (2-4 $\mu \mathrm{M})$ declined much faster and were lower compared to the higher kinetin levels, except plant height and the number of roots which were still higher at the moderate kinetin level even after eight weeks of culturing.

\section{Conclusions}

Use of nodal segments and MS medium amended with kinetin promoted direct regeneration of Akaaba, a D. alata cultivar, without callus formation. The application of surface response model provided an effective means to better elucidate the effects of kinetin on $D$. alata propagated in vitro. Temporal trends and how various growth parameters were affected differently by different kinetin levels were easily identified. In general, moderate kinetin levels (2-4 $\mu \mathrm{M})$ were required to provide better growth at early culturing period. Higher kinetin levels (5-10 $\mu \mathrm{M})$ suppressed the growth of the plantlets at early stages, but the plantlets recovered from the stress and resumed normal growth thereafter. After 4-5 weeks, the growth rates (number of shoots and roots formed per week) of the moderate kinetin levels (2-4 $\mu \mathrm{M})$ declined much faster and were lower compared to the higher kinetin levels. However, the increase in plant height and the number of leaves were still high at the moderate kinetin level even after eight weeks of culturing. In general, different kinetin levels have variable temporal effects on the growth of $D$. alata plantlets propagated in vitro, and kinetin requirement will vary depending on the growth parameters of interest.

\section{Acknowledgments}

The study was supported by funds and facilities provided by the Department of Crop and Soil Sciences, Kwame Nkrumah University of Science and Technology, Kumasi, Ghana.

\section{References}

[1] Asiedu, R., and Sartie, A. 2010. "Crops That Feed the World 1: Yams.” Food Secur. 2 (4): 305-15.

[2] Aighewi, B. A., Maroya, N. G., and Asiedu, R. 2014. Seed Yam Production from Minisetts: A Training Manual. Ibadan, Nigeria: International Institute of Tropical Agriculture (IITA).

[3] Mahesh, R., Muthuchelian, K., Maridass, M., Raju, G., Article, O., Studies, F., and Nadu, T. 2010. "In Vitro Propagation of Wild Yam, Dioscorea wightii through Nodal Cultures.” Int. J. Biol. Technol. 1 (1): 111-3.

[4] FAO. 2016. "Total World Production of Yams in 2014." FAOSTAT. Accessed October 29, 2016. http://www.fao.org/faostat/en/\#data.

[5] Aighewi, B. A., Asiedu, R., Maroya, N., and Balogun, M. 2015. "Improved Propagation Methods to Raise the Productivity of Yam (Dioscorea rotundata Poir.).” Food Secur. 7 (4): 823-34.

[6] Oselebe, H. O., and Okporie, E. O. 2008. "Evaluation of 
Water Yam (Dioscorea alata L.) Genotypes for Yield and Yield Components in Abakaliki Agro-ecological Zone of Nigeria.” Agro-Science 7 (3): 179-85.

[7] Demuyakor, B., Dukrog, T. M., and Chikpah, S. K. 2013. "Yam Germplasm in Ghana-A Survey on Storage and Varietal Properties of Dioscorea rotundata-alata in Northern Region of Ghana.” Int. J. Sci. Technol. Res. 2 (1): 170-5.

[8] Ironkwe, A. G., Asiedu, R., and Unamma, R. P. A. 2007. "Adoption of Yam Minisett Technology by Women Farmers in Abia State, Nigeria.” J. Agric. Soc. Res. 7 (2): 95-105.

[9] Ogbonna, M. C., Korieocha, D. S., Onyenobi, V. O., and Njoku, S. C. 2011. "Profitability of Minituber Seed Yam Production Technique in South East Agro-Ecological Zone: Evidence from Abia State, Nigeria.” J. Agric. Soc. Res. 11 (2): 113-9.

[10] Asumugha, G. N., and Ogbonna, M. C. 2013. Promotion of Improved Yam Minisett Technology to Improve Productivity and Reduce Excessive Use of Food Yam for Planting in Ghana, Nigeria, Togo and Benin. Dakar, Senegal: CORAF/WECARD.

[11] Nweke, F. I. 2014. Yam in West Africa: Food, Money and More. East Lansing, MI: Michigan State University Press.

[12] Alam, I., Sharmin, S. A., Naher, K., Alam, J., Anisuzzaman, M., and Alam, M. F. 2010. "Effect of Growth Regulators on Meristem Culture and Plantlet Establishment in Sweet Potato, Ipomoea batatas (L.) Lam..” Plant Omics. 3 (2): 35-9.

[13] Ngomuo, M., Mneney, E., and Ndakidemi, P. A. 2014. "The in Vitro Propagation Techniques for Producing Banana Using Shoot Tip Cultures.” Am. J. Plant Sci. 5 (11): 1614-22.

[14] Sintim, H. Y., and Akromah, R. 2015. "Differing Sucrose Requirements for in Vitro Conservation of Cassava Genotypes.” Int. J. Plant Soil Sci. 7 (1): 45-54.

[15] Yam, T. W., and Arditti, J. 2009. "History of Orchid Propagation: A Mirror of the History of Biotechnology.” Plant Biotechnol. Rep. 3 (1): 1-56.

[16] Amissah, S., Coleman, P. A., Sintim, H. Y., and Akromah, R. 2016. "In Vitro Control of Microbial Contamination of Sweet Potatoes Cultured with Nodal Explants.” Ann. Res. Rev. Biol. 9 (3): 1-8.

[17] Yuan, S., Yan, Y. C., and Lin, H. H. 2005. "Plant Regeneration through Somatic Embryogenesis from Callus Cultures of Dioscorea zingiberensis.” Plant Cell, Tissue Organ Cult. 80 (2): 157-61.

[18] Anwar, N., Kikuchi, A., and Watanabe, K. N. 2010. "Assessment of Somaclonal Variation for Salinity Tolerance in Sweet Potato Regenerated Plants.” African J. Biotechnol. 9 (43): 7256-65.
[19] Borges, M., Ceiro, W., Meneses, S., Aguilera, N., Vázquez, J., Infante, Z., and Fonseca, M. 2004. "Regeneration and Multiplication of Dioscorea alata Germplasm Maintained in Vitro.” Plant Cell, Tissue Organ Cult. 76 (1): 87-90.

[20] Behera, K. K., Sahoo, S., and Prusti, A. 2008. "Effect of Plant Growth Regulator on in Vitro Micropropagation of ‘Bitter Yam' (Dioscorea hispida Dennst.).” Int. J. Integr. Biol. 4 (1): 50-4.

[21] Fotso, F., Sandrine, N. N. M. F., Désiré, M. H., François, D. P., and Denis, O. N. 2013. "Micropropagation of Dioscorea alata L. from Microtubers Induced in Vitro." African J. Biotechnol. 12 (10): 1057-67.

[22] Shukla, S., and Shukla, S. K. 2014. "In Vitro Regeneration of Dioscorea hispida through Nodal Explants-A Rich Source of Starch.” GSTF J. Biosci. 3 (1): 30-5.

[23] Poornima, G. N., and Ravishankar, R. V. 2007. “In Vitro Propagation of Wild Yams, Dioscorea oppositifolia (Linn) and Dioscorea pentaphylla (Linn).” African J. Biotechnol. 6 (20): 2348-52.

[24] Behera, K. K., Sahoo, S., and Prusti, A. 2009. "Regeneration of Plantlet of Water Yam (Dioscorea oppositifoliaa L.) through in Vitro Culture from Nodal Segments.” Not. Bot. Hort. Agrobot. Cluj-Napoca 37 (1): 94-102.

[25] Das, S., Manabendra, D. C., and Pranab, B. M. 2013. "Micropropagation of Dioscorea alata L. through Nodal Segments.” African J. Biotechnol. 12 (47): 6611-7.

[26] Amasino, R. 2005. "1955: Kinetin Arrives-The 50th Anniversary of a New Plant Hormone.” Plant Physiol. 138 (3): 1177-84.

[27] R Core Team. 2016. R: A Language and Environment for Statistical Computing. Vienna, Austria: R Foundation for Statistical Computing.

[28] Sita, G. L., Bammi, R. K., and Randhawa, G. S. 1976. "Clonal Propagation of Dioscorea floribunda by Tissue Culture.” J. Hortic. Sci. 51 (4): 551-4.

[29] Chen, Y. Q., Fan, J. Y., Yi, F., Luo, Z. X., and Fu, Y. S. 2003. "Rapid Clonal Propagation of Dioscorea zingiberensis.” Plant Cell, Tissue Organ Cult. 73 (1): 75-80.

[30] Bahmani, R., Karami, O., and Gholami, M. 2009. "Influence of Carbon Sources and Their Concentrations on Rooting and Hyperhydricity of Apple Rootstock MM. 106.” World Appl. Sci. J. 6 (11): 1513-7.

[31] Mantell, S. H., and Hugo, S. A. 1989. "Effects of Photoperiod, Mineral Medium Strength, Inorganic Ammonium, Sucrose and Cytokinin on Root, Shoot and Microtuber Development in Shoot Cultures of Dioscorea alata L. and D. bulbifera L. Yams.” Plant Cell, Tissue Organ Cult. 16 (1): 23-37. 